\title{
Quality of life after acute coronary syndrome; a comparative study
}

\author{
Hasheni BV ${ }^{1}$, Somasiri $\mathbf{K G}^{2}$ \\ ${ }^{\prime}$ Teaching Hospital, Karapitiya, Galle, Sri Lanka \\ ${ }^{2}$ Faculty of Medicine, University of Ruhuna, Galle, Sri Lanka
}

Correspondence: Dr.B.V.Hasheni; (bvhasheni@yahoo.co.uk)

\begin{abstract}
Introduction: Quality of life (QOL) is a measure based on patients' perspective. Measurement of QOL is useful in the evaluation of cardiac diseases.

Methods: QOL scores of patient with the diagnosis of acute coronary syndrome were assessed using WHOQOL-100 questionnaire one month and three months after being discharged from hospital. QOL scores of patients were compared with that of the controls and scores of one month after discharge with that of three months after discharge.

Results: 56 and 30 patients out of 111 responded for the assessment at one month and three months after the discharge respectively. There were 45 in the control group.

QOL scores for physical capacity (PC), psychological aspects (PSY) and level of independence (LOI) were significantly lower in patients than the controls at one month after discharge. The scores of one month after discharge with the scores of three months after discharge showed significant differences in PC and LOI.

Conclusions: The QOL scores of PC, PSY and LOI domains are lower in patients who had acute coronary syndrome than in controls. There is improvement in PC and LOI scores with time from one month to three months after getting discharged from the hospital.
\end{abstract}

Key words: Quality of Life, WHOQOL-100, Acute Coronary Syndrome

\section{Introduction}

The impact of the management of a patient is traditionally assessed by the clinician on the basis of clinical findings. Patients' perception has not being considered as an important factor in the traditional assessment. Health related quality of life (HRQOL) is developed to assess the patients' perception about the disease. HRQOL is used to assess the progress of the disease as well as to compare the different management methods $(1,2,3)$. Furthermore, it can be used to asses the effect of treatment (2). There are studies to show that QOL assessment can be used to find the effect of cardiac rehabilitation programmes $(4,5)$.

There are number of instruments developed to assess the quality of life. Those instruments can be divided into two types. There are generic instruments and disease specific instruments. SF 36, GHQ and WHOQOL are examples for generic instruments. There are disease specific instruments to assess quality of life of patients with different diseases. Mac New questionnaire (4) and Seattle Angina Questionnaire are disease specific instruments used to assess quality of life in patients with heart diseases.

Most generic instruments assess different aspects of quality of life. There are number of questions to assess different aspects of QOL. Most instruments assess physical, mental and social aspects of the individual.

WHOQOL has been developed by the WHO and it is validated to be used in different cultures (6). 
The WHOQOL instrument has been translated to Sinhala and validated (7). WHOQOL has WHOQOL-100 version as well as BREF version. WHOQOL-100 assesses quality of life in 24 facets and quality of life in general. There are four questions to assess each facet. Combining different facets, six domains have been developed to assess QOL. The domains assessed by WHOQOL-100 are physical capacity, psychological aspects, social relationships, living environment, level of independence and spirituality.

Quality of life of patients with cardiac conditions are measured using generic quality of life measuring instruments $(2,3,8,9)$ as well as disease specific instruments (4). Health related quality of life measurement has been successfully used in other countries to compare two cardiac rehabilitation methods in patients with coronary artery disease (5). However such studies are rare to find in local set up. In one local study it has been shown that quality of life scores as measured by WHOQOL are lower in hypertensive patients followed up at clinics of Teaching hospital, Karapitiya compared to healthy subjects (10). We were unable to find local data on health related quality of life among patients with acute coronary syndrome.

Results of the QOL studies done using other generic instruments indicates that QOL is lower in patient who had acute coronary event four years previously than in a comparable group of healthy individuals (3). There are studies to indicate that QOL is lower within first 3 - 4 months after an acute coronary event $(11,12)$. Using SF-36, Failda and Soto (11) have shown that health related quality of life scores are low three months after an acute coronary syndrome and this was most evident in the physical component.

The aim of the study was to study the QOL of patients after acute coronary event and changes in QOL with standard management at Teaching Hospital, Karapitiya.

\section{Methods}

All patients who have been discharged from the Cardiology unit and Medical wards of the Teaching Hospital, Karapitiya, Galle, with the diagnosis of acute myocardial infarction or unstable angina
(ACS) from 1st of April 2009 to 31 at July 2009 were enrolled to the study. Age and sex matched bystanders of other patients in the same wards were selected as the control group. The Sinhala translation of WHOQOL-100 was self administered to patients on two occasions and on one occasion to the control group.

All patients discharged from the respective unit and wards during the study period were given two copies of WHOQOL-100 questionnaire at the time of discharge with two stamped envelopes carrying the address of the principal investigator. They were requested to fill the questionnaire separately at the end of one month and three months after the acute coronary event. WHOQOL-100 was administered to a control group while they were in the ward as bystanders. Written consent was obtained from all participants. Ethical approval was obtained from the Ethical Review Committee of the Faculty of Medicine, University of Ruhuna before the commencement of the study.

Scores for different facets and domains were calculated as described in the manual of the WHOQOL. Independent $t$-test was used to compare the mean differences of quality of life scores of patients with that of the control group (Table 1). Paired t-test was used to compare the quality of life scores of patients at one month and at three months after the acute coronary syndrome (Table 2 ).

\section{Results}

Fifty six patients out of 111 had responded by sending the filled questionnaire one month after the coronary event and only 30 patients had responded three months after the coronary event. There were 45 participants in the control group.

The age range of the patients who had responded one month after coronary event was $38-81$ yrs with a mean of 58.6 years. The age range of the control group was $20-73$ yrs with a mean of 54.7 years. The age range of the patients who had responded three months after discharge was $38-81$ yrs with a mean of 59.9 years. Female to male ratios of the control group and the patient group responded one month after coronary event were, $1: 1$ and 1:1.4, respectively. Female to male ratio of the patient group responded at three months was 1:1.3. 
Table 1: Comparison of QOL scores of patient groups responded one month and three months after coronary event with the QOL scores of the control group

\begin{tabular}{|c|c|c|c|c|c|}
\hline \multirow[b]{2}{*}{ Domain/ Facet } & \multirow{2}{*}{$\begin{array}{l}\text { Controls } \\
\mathrm{n}=45 \\
\text { Mean( SD) } \\
\end{array}$} & \multicolumn{2}{|l|}{$\begin{array}{l}1 \text { month } \\
\mathrm{n}=56\end{array}$} & \multicolumn{2}{|l|}{$\begin{array}{l}3 \text { months } \\
\mathrm{n}=30\end{array}$} \\
\hline & & Mean(SD) & $\mathrm{P}^{*}$ & Mean(SD) & $\mathrm{P}^{* *}$ \\
\hline Physical capacity & $67.6 \pm \mathbf{1 3 . 5}$ & $53.1 \pm 19.1$ & $<0.001$ & $57.7 \pm \mathbf{1 8 . 3}$ & 0.09 \\
\hline Pain and discomfort & $35.3 \pm 16.7$ & $50.5 \pm 21.0$ & $<0.001$ & $45.6 \pm 20.8$ & 0.02 \\
\hline Energy and fatigue & $67.9 \pm 17.0$ & $49.9 \pm 21.4$ & $<0.001$ & $55.4 \pm 20.6$ & 0.005 \\
\hline Sleep and rest & $70.1 \pm 18.2$ & $59.9 \pm 25.0$ & 0.024 & $63.3 \pm 22.3$ & 0.152 \\
\hline Psychological & $69.8 \pm 12.9$ & $63.1 \pm 15.4$ & 0.022 & $64.2 \pm 14.6$ & 0.087 \\
\hline Positive feelings & $70.8 \pm 15.7$ & $59.8 \pm 21.9$ & 0.005 & $61.8 \pm 21.0$ & 0.036 \\
\hline $\begin{array}{l}\text { Thinking, learning, memory } \\
\text { and concentration }\end{array}$ & $65.0 \pm 15.1$ & $61.7 \pm 18.5$ & 0.339 & $62.2 \pm 19.0$ & 0.484 \\
\hline Self esteem & $73.6 \pm 14.9$ & $71.9 \pm 18.1$ & 0.629 & $69.4 \pm 18.8$ & 0.281 \\
\hline Body image and appearance & $73.9 \pm 19.3$ & $66.8 \pm 22.0$ & 0.092 & $68.2 \pm 22.5$ & 0.246 \\
\hline Negative feelings & $34.6 \pm 18.2$ & $45.0 \pm 24.0$ & 0.018 & $40.6 \pm 27.0$ & 0.250 \\
\hline Level of independence & $73.0 \pm 15.4$ & $48.5 \pm 17.3$ & $<0.001$ & $52.3 \pm 17.6$ & $<0.001$ \\
\hline Mobility & $72.5 \pm 19.4$ & $51.6 \pm 23.3$ & $<0.001$ & $54.2 \pm 22.7$ & 000 \\
\hline Activities of daily living & $70.4 \pm 18.1$ & $55.5 \pm 22.6$ & 0.001 & $64.0 \pm 23.4$ & 0.183 \\
\hline $\begin{array}{l}\text { Dependence on medication } \\
\text { or treatment }\end{array}$ & $22.1 \pm 17.9$ & $61.9 \pm 21.3$ & 000 & $61.7 \pm 21.4$ & 000 \\
\hline Work capacity & $71.0 \pm 18.7$ & $49.1 \pm 19.0$ & 000 & $52.9 \pm 18.7$ & 000 \\
\hline Social relationships & $64.1 \pm 12.5$ & $57.9 \pm 18.6$ & 0.056 & $57.6 \pm 19.2$ & 0.081 \\
\hline Personal relationships & $71.0 \pm 12.5$ & $58.7 \pm 21.3$ & 0.001 & $62.4 \pm 21.4$ & 0.032 \\
\hline Social support & $57.8 \pm 17.7$ & $58.2 \pm 22.1$ & 0.913 & $55.4 \pm 23.3$ & 0.620 \\
\hline Sexual activity & $63.9 \pm 17.8$ & $56.3 \pm 22.7$ & 0.084 & $53.3 \pm 23.2$ & 0.043 \\
\hline Environment & $61.1 \pm 12.1$ & $60.0 \pm 14.7$ & 0.683 & $59.0 \pm 14.7$ & 0.50 \\
\hline Physical Safety and Security & $67.6 \pm 15.8$ & $69.9 \pm 21.0$ & 0.543 & $68.5 \pm 19.7$ & 0.827 \\
\hline Home environment & $69.7 \pm 16.4$ & $71.0 \pm 20.0$ & 0.734 & $69.8 \pm 20.2$ & 0.987 \\
\hline Financial resources & $56.1 \pm 21.4$ & $42.7 \pm 26.4$ & 0.007 & $42.5 \pm 28.2$ & 0.02 \\
\hline $\begin{array}{l}\text { Health and social care: } \\
\text { accessibility and quality }\end{array}$ & $52.9 \pm 16.1$ & $57.6 \pm 19.4$ & 0.198 & $55.8 \pm 17.6$ & 0.471 \\
\hline Opportunities for acquiring & & & & & \\
\hline new information and skills & $52.7 \pm 19.3$ & $47.0 \pm 21.3$ & 0.164 & $49.6 \pm 17.7$ & 0.478 \\
\hline Participation in and opportunities & & & & & \\
\hline for recreation/ leisure activities & $65.6 \pm 19.6$ & $66.0 \pm 18.9$ & 0.901 & $65.8 \pm 19.2$ & 0.952 \\
\hline Physical Environment & $68.7 \pm 14.0$ & $71.2 \pm 18.1$ & 0.457 & $66.7 \pm 18.1$ & 0.577 \\
\hline Transport & $55.2 \pm 24.3$ & $54.2 \pm 25.5$ & 0.843 & $53.1 \pm 26.5$ & 0.724 \\
\hline Spirituality /Religion/ & & & & & \\
\hline Personal Beliefs & $68.5 \pm 18.2$ & $60.4 \pm 17.2$ & 0.024 & $60.4 \pm 17.6$ & 0.061 \\
\hline $\begin{array}{l}\text { Overall quality of life and } \\
\text { general health }\end{array}$ & $66.0 \pm 19.6$ & $56.8 \pm 18.7$ & 0.018 & $57.8 \pm 18.9$ & 0.076 \\
\hline
\end{tabular}

p* contrast QOL scores of 1 month vs controls, $p * *$ contrast QOL scores of 3 month vs controls

The scores of physical capacity, psychological and level of independence of patients who had an episode of ACS one month ago were significantly lower than those of the control group. The score of level of independence was lower in patients three months after ACS than that of the healthy controls. 
Table 2: Comparison of QOL domain scores of patients one month after and three months after coronary event (paired t-test)

Number of patients 30

\begin{tabular}{|c|c|c|c|}
\hline Domain & $\begin{array}{l}1 \text { month } \\
\text { Mean (SD) }\end{array}$ & $\begin{array}{l}3 \text { months } \\
\text { Mean (SD) }\end{array}$ & $\mathrm{P}$ \\
\hline Physical capacity & $50.8 \pm 18.6$ & $57.7 \pm 18.3$ & 0.005 \\
\hline Pain and discomfort & $54.5 \pm 18.9$ & $45.6 \pm 20.8$ & 0.021 \\
\hline Energy and fatigue & $48.3 \pm 20.6$ & $55.4 \pm 20.6$ & 0.023 \\
\hline Sleep and rest & $58.5 \pm 24.9$ & $63.3 \pm 22.3$ & 0.091 \\
\hline Psychological & $61.6 \pm 14.5$ & $64.2 \pm 14.6$ & 0.16 \\
\hline Positive feelings & $58.6 \pm 23.8$ & $61.8 \pm 21.0$ & 0.263 \\
\hline $\begin{array}{l}\text { Thinking, learning, memory and } \\
\text { concentration }\end{array}$ & $57.7 \pm 15.7$ & $62.2 \pm 19.0$ & 0.102 \\
\hline Self-esteem & $70.4 \pm 18.6$ & $69.4 \pm 18.8$ & 0.572 \\
\hline Bodily image and appearance & $67.6 \pm 22.8$ & $68.2 \pm 22.5$ & 0.856 \\
\hline Negative feelings & $46.3 \pm 25.2$ & $40.6 \pm 27.0$ & 0.100 \\
\hline Level of independence & $47.2 \pm 15.8$ & $52.3 \pm 17.6$ & 0.028 \\
\hline Mobility & $51.3 \pm 22.8$ & $54.2 \pm 22.7$ & 0.467 \\
\hline Activities of daily living & $52.7 \pm 21.3$ & $64.0 \pm 23.4$ & 0.005 \\
\hline Dependence on medication or treatment & $64.2 \pm 19.8$ & $61.7 \pm 21.4$ & 0.432 \\
\hline Work capacity & $49.0 \pm 20.0$ & $52.9 \pm 18.7$ & 0.344 \\
\hline Social relationships & $57.9 \pm 17.4$ & $57.6 \pm 19.2$ & 0.892 \\
\hline Personal relationships & $59.2 \pm 21.9$ & $62.4 \pm 21.4$ & 0.179 \\
\hline Social support & $58.9 \pm 21.6$ & $55.4 \pm 23.3$ & 0.317 \\
\hline Sexual activity & $54.6 \pm 20.9$ & $53.3 \pm 23.2$ & 0.741 \\
\hline Environment & $58.9 \pm 14.5$ & $58.9 \pm 14.6$ & 0.995 \\
\hline Physical safety and security & $66.0 \pm 25.3$ & $68.5 \pm 19.7$ & 0.490 \\
\hline Home environment & $70.4 \pm 21.6$ & $69.8 \pm 20.2$ & 0.801 \\
\hline Financial resources & $42.5 \pm 26.9$ & $42.5 \pm 28.1$ & 1.0 \\
\hline $\begin{array}{l}\text { Health and social care; } \\
\text { accessibility and quality }\end{array}$ & $57.3 \pm 18.1$ & $55.8 \pm 17.6$ & 0.421 \\
\hline $\begin{array}{l}\text { Opportunities for accruing new } \\
\text { information and skills }\end{array}$ & $48.5 \pm 17.0$ & $49.6 \pm 17.7$ & 0.612 \\
\hline $\begin{array}{l}\text { Participate in and opportunities } \\
\text { for recreation / leisure activities }\end{array}$ & $64.9 \pm 20.1$ & $65.8 \pm 19.2$ & 0.717 \\
\hline Physical environment & $71.3 \pm 16.2$ & $66.7 \pm 18.1$ & 0.088 \\
\hline Transport & $50.8 \pm 25.8$ & $53.1 \pm 26.5$ & 0.423 \\
\hline Spirituality / Religion / Personal Beliefs & $60.2 \pm 14.3$ & $60.4 \pm 17.6$ & 0.862 \\
\hline Overall quality of life and general health & $57.3 \pm 17.5$ & $57.7 \pm 18.9$ & 0.862 \\
\hline
\end{tabular}

Comparison of the scores of one month after ACS with those of three months after the ACS showed a significant improvement of the quality of life in domains physical capacity and level of independence.

There is no significant improvement in other domains. 
Table 3: Comparison of QOL scores between male and females

\begin{tabular}{|c|c|c|c|c|c|c|}
\hline \multirow[b]{3}{*}{ Domain/ Facet } & \multicolumn{2}{|c|}{1 month } & \multicolumn{4}{|c|}{3 months } \\
\hline & \multirow{2}{*}{$\begin{array}{l}\text { Female } \\
\mathrm{n}=23 \\
\text { Mean \& SD }\end{array}$} & \multirow{2}{*}{$\begin{array}{l}\text { Male } \\
\mathrm{n}=33 \\
\text { Mean \& SD }\end{array}$} & \multirow[b]{2}{*}{$\mathrm{P}$} & \multirow{2}{*}{$\begin{array}{l}\text { Female } \\
\mathrm{n}=13 \\
\text { Mean \& SD }\end{array}$} & \multirow{2}{*}{$\begin{array}{l}\text { Male } \\
\mathrm{n}=17 \\
\text { Mean \& SD }\end{array}$} & \multirow[b]{2}{*}{$\mathrm{P}$} \\
\hline & & & & & & \\
\hline Physical capacity & $59.7 \pm 21.2$ & $48.5 \pm 16.2$ & 0.029 & $63.6 \pm 19.4$ & $53.2 \pm 16.7$ & 0.124 \\
\hline Pain and discomfort & $42.7 \pm 22.8$ & $56.0 \pm 17.9$ & 0.018 & $44.2 \pm 19.7$ & $46.7 \pm 22.2$ & 0.755 \\
\hline Energy and fatigue & $55.2 \pm 25.2$ & $46.2 \pm 17.8$ & 0.125 & $60.6 \pm 24.0$ & $51.5 \pm 17.3$ & 0.237 \\
\hline Sleep and rest & $66.6 \pm 25.5$ & $55.3 \pm 23.9$ & 0.097 & $74.5 \pm 22.9$ & $54.8 \pm 18.2$ & 0.152 \\
\hline Psychological & $66.0 \pm 16.3$ & $61.0 \pm 14.7$ & 0.242 & $67.7 \pm 16.0$ & $61.5 \pm 13.2$ & 0.258 \\
\hline Positive feeling & $63.3 \pm 22.1$ & $57.4 \pm 21.7$ & 0.323 & $68.3 \pm 15.0$ & $56.90 \pm 23.9$ & 0.143 \\
\hline $\begin{array}{l}\text { Thinking, learning, memory } \\
\text { and concentration }\end{array}$ & $59.5 \pm 16.8$ & $63.3 \pm 19.7$ & 0.461 & $61.5 \pm 17.1$ & $62.7 \pm 20.8$ & 0.866 \\
\hline Self esteem & $73.6 \pm 15.9$ & $70.8 \pm 19.6$ & 0.572 & $73.1 \pm 16.0$ & $66.5 \pm 20.7$ & 0.355 \\
\hline Body image and appearance & $70.9 \pm 25.5$ & $63.9 \pm 19.1$ & 0.243 & $67.3 \pm 31.9$ & $68.9 \pm 12.4$ & 0.854 \\
\hline Negative feelings & $37.5 \pm 24.1$ & $50.2 \pm 22.8$ & 0.051 & $31.7 \pm 23.6$ & $47.4 \pm 28.1$ & 0.250 \\
\hline Level of independence & $51.8 \pm 22.8$ & $46.3 \pm 12.0$ & 0.249 & $55.2 \pm 23.6$ & $50.2 \pm 11.5$ & 0.452 \\
\hline Mobility & $55.7 \pm 27.5$ & $48.7 \pm 19.9$ & 0.271 & $59.1 \pm 32.5$ & $50.4 \pm 10.2$ & 0.303 \\
\hline Activities of daily living & $60.9 \pm 26.7$ & $51.7 \pm 18.9$ & 0.138 & $70.2 \pm 27.4$ & $59.2 \pm 19.3$ & 0.207 \\
\hline $\begin{array}{l}\text { Dependence on medication } \\
\text { or treatment }\end{array}$ & $55.7 \pm 24.4$ & $66.3 \pm 17.9$ & 0.066 & $56.7 \pm 24.8$ & $65.4 \pm 18.4$ & 0.278 \\
\hline Work capacity & $46.2 \pm 23.8$ & $51.1 \pm 14.9$ & 0.344 & $48.1 \pm 20.9$ & $56.6 \pm 16.5$ & 0.221 \\
\hline Social relationships & $59.0 \pm 18.6$ & $57.0 \pm 18.8$ & 0.699 & $61.4 \pm 18.5$ & $54.7 \pm 19.8$ & 0.353 \\
\hline Personal relationships & $60.7 \pm 23.7$ & $57.3 \pm 19.6$ & 0.565 & $70.5 \pm 20.2$ & $56.3 \pm 20.7$ & 0.069 \\
\hline Social support & $60.0 \pm 20.7$ & $57.0 \pm 23.2$ & 0.627 & $59.6 \pm 20.5$ & $52.2 \pm 25.4$ & 0.398 \\
\hline Sexual activity & $55.6 \pm 19.2$ & $56.8 \pm 25.0$ & 0.846 & $50.4 \pm 23.0$ & $55.7 \pm 23.9$ & 0.584 \\
\hline Environment & $60.7 \pm 14.7$ & $59.5 \pm 14.9$ & 0.762 & $62.0 \pm 12.8$ & $56.7 \pm 16.0$ & $\mathbf{0 . 3 3 3}$ \\
\hline Physical Safety and security & $69.6 \pm 20.7$ & $70.2 \pm 21.5$ & 0.912 & $73.6 \pm 16.0$ & $64.7 \pm 21.9$ & 0.230 \\
\hline Home environment & $75.3 \pm 19.1$ & $68.0 \pm 20.3$ & 0.182 & $75.4 \pm 19.5$ & $65.4 \pm 20.1$ & 0181 \\
\hline Financial resources & $50.0 \pm 25.6$ & $37.7 \pm 26.1$ & 0.086 & $43.8 \pm 27.2$ & $41.5 \pm 29.6$ & 0.836 \\
\hline $\begin{array}{l}\text { Health and social care: } \\
\text { accessibility and quality }\end{array}$ & $52.4 \pm 19.0$ & $61.2 \pm 19.1$ & 0.098 & $53.4 \pm 14.3$ & $57.6 \pm 19.9$ & 0.523 \\
\hline $\begin{array}{l}\text { Opportunities for acquiring } \\
\text { new information and skills }\end{array}$ & $46.2 \pm 20.9$ & $47.5 \pm 21.8$ & 0.819 & $50.0 \pm 16.9$ & $49.3 \pm 18.9$ & 0.913 \\
\hline $\begin{array}{l}\text { Participation in and } \\
\text { opportunities for recreation / } \\
\text { activities }\end{array}$ & $67.0 \pm 17.1$ & $65.3 \pm 20.3$ & 0.746 & $73.6 \pm 17.5$ & $59.9 \pm 18.8$ & $\begin{array}{l}\text { leisure } \\
0.052\end{array}$ \\
\hline Physical environment & $67.7 \pm 17.4$ & $73.7 \pm 18.4$ & 0.225 & $67.6 \pm 18.1$ & $65.9 \pm 18.7$ & 0.805 \\
\hline Transport & $57.3 \pm 22.4$ & $52.1 \pm 27.6$ & 0.453 & $58.7 \pm 24.1$ & $48.9 \pm 28.1$ & 0.326 \\
\hline Spirituality / Religion / & & & & & & \\
\hline Personal Beliefs & $60.3 \pm 20.0$ & $60.4 \pm 15.2$ & 0.985 & $61.5 \pm 15.1$ & $59.6 \pm 19.8$ & 0.766 \\
\hline $\begin{array}{l}\text { Overall quality of life and } \\
\text { general health }\end{array}$ & $56.5 \pm 22.0$ & $57.0 \pm 16.4$ & 0.925 & $63.5 \pm 18.9$ & $53.4 \pm 18.3$ & 0.153 \\
\hline
\end{tabular}


Comparison of QOL sores of the males with those of females at the end of one month showed significantly higher values in females than in males for the domain of physical capacity. This significant difference was not found at the end of three months after the discharge from the hospital. There was a tendency for higher QOL scores in females than in males for all domains (except for the domain of spirituality-) though the differences were not significant.

Table 4: QOL domain scores of myocardial infarction (MI) and unstable angina (UA) one month and 3 months after discharge from hospital

\begin{tabular}{lllllll}
\hline & \multicolumn{2}{c}{ 1 month } & \multicolumn{3}{c}{ 3 months } \\
DA & UI & & UA & MI & \\
& $\begin{array}{l}\text { Mean \& SD } \\
\mathrm{n}=37\end{array}$ & $\begin{array}{l}\text { Mean \& SD } \\
\mathrm{n}=19\end{array}$ & $\mathrm{P}$ & $\begin{array}{l}\text { Mean \& SD } \\
\mathrm{n}=19\end{array}$ & $\begin{array}{l}\text { Mean \& SD } \\
\mathrm{n}=11\end{array}$ & $\mathrm{P}$ \\
\hline Physical capacity & $57.4 \pm 20.4$ & $49.9 \pm 16.3$ & $\mathrm{~ns}$ & $58.4 \pm 17.7$ & $56.4 \pm 20.1$ & $\mathrm{~ns}$ \\
Psychological & $64.6 \pm 16.0$ & $60.0 \pm 14.3$ & $\mathrm{~ns}$ & $67.0 \pm 14.7$ & $59.3 \pm 13.7$ & $\mathrm{~ns}$ \\
Level of independence & $50.4 \pm 17.4$ & $45.0 \pm 17.1$ & $\mathrm{~ns}$ & $55.6 \pm 13.6$ & $46.7 \pm 22.6$ & $\mathrm{~ns}$ \\
Social relationships & $58.0 \pm 19.5$ & $57.6 \pm 17.1$ & $\mathrm{~ns}$ & $59.2 \pm 19.1$ & $54.9 \pm 20.0$ & $\mathrm{~ns}$ \\
Environment & $61.2 \pm 15.8$ & $57.5 \pm 12.3$ & $\mathrm{~ns}$ & $61.0 \pm 16.0$ & $55.4 \pm 11.8$ & $\mathrm{~ns}$ \\
Spirituality & $62.2 \pm 16.6$ & $56.9 \pm 18.1$ & $\mathrm{~ns}$ & $66.8 \pm 15.2$ & $49.4 \pm 16.6$ & 0.01 \\
\hline
\end{tabular}

Comparison of QOL domain scores of unstable angina with domain scores of acute myocardial infarction did not show statistically significant difference. Though there is no statistically significant difference between the two groups it showed a pattern that there was a tendency to have lower scores in myocardial infarction than in unstable angina.

\section{Discussion}

The results of the study showed that QOL scores as assessed by WHOQOL-100 were lower after acute coronary event when compared with healthy population. These findings are compatible with the results of other studies $(3,8,9)$. The differences were higher in level of independence, physical and psychological domains. There are no studies on QOL scores done using WHOQOL in the literature for direct comparison. Comparison of studies done with other generic instruments has also shown that physical aspect is more affected than the other aspects $(2,9)$. There are some studies done using other instruments to find the QOL of patients after acute coronary events showing similar findings to our results $(3,9)$.

Comparison of QOL scores of control group and QOL scores of patients one month and three months after ACS showed that QOL was lower after ACS.
It also showed that there was an improvement in QOL three months after the event when compared with the values of one month after the event. Improvement was mainly seen in domains of physical capacity, psychological, level of independence and social relationships. There was no change in scores of environment and spirituality domains. Comparison of QOL scores of one month after with those of three months after indicated a significant improvement of QOL in physical and level of independence domains.

Comparison of QOL scores between females and males showed that QOL was better in females than males after ACS. Though the differences were not statistically significant the same pattern was seen in all domains except spirituality. In this domain, scores were similar in both sexes. The scores for facets such as work capacity, sexual activity, participation in leisure activities and transport were higher in males than in females. In contrast to our 
study Brink et al found that, women have significantly lower scores than men for physical component (PCS) one year after the acute myocardial infarction (8).

Hofer et al have shown an improvement of QOL with time after a cardiac event (4). Our results also showed an improvement in QOL three months after the acute coronary event when compared with scores at the end of one month. Hofers et al have assessed QOL both before and after the rehabilitation programme (4). In our study there was no formal rehabilitation programme as such but patients were managed in the outpatient clinics. Brown et al observed lower QOL even four years after myocardial infarction when compared with normal population (3). In our study we have included myocardial infarction as well as unstable angina. The other major difference in our study was that we have assessed QOL using WHOQOL whereas Brown et al have assessed QOL using SF 36 and they have found that physical component is more affected than other components (3). In our study level of independence was more affected than physical capacity. There is no comparable domain to level of independence in SF 36.

QOL domain scores of unstable angina and acute myocardial infarction did not show statistically significant differences. However, there was a tendency for patients who had acute myocardial infarction to have lower scores compared to the patients who had unstable angina. This pattern was seen in all domains both one month and three months after a coronary event.

\section{Limitations}

The main limitation in this study was poor response rate. Only 56 patients out of 111 recruits had responded by sending forms at one month and the response rate had further reduced at 3 months.

\section{Conclusions}

The QOL as assessed by WHOQOL-100 is lower in patients after an acute coronary event than that of the healthy people. The pattern remains the same even after three months from an acute coronary event. There is a significant improvement in quality of life at three months after ACS when compared with the
QOL of one month after ACS. The improvement is seen only in physical capacity, level of independence and psychological domains.

\section{References}

1. L-Y Lim L, Valenti LA, et al. A self-administered qualityof-life questionnaire after acute myocardial infarction. JClin Epidemiol 1993; 46(11): 1249-56.

2. Mortensen OS, Madsen KJ, et al. Health related quality of life after conservative or invasive treatment of inducible postinfarction ischemia. Heart 2000; 84: 535-40.

3. Brown N, Melville M, et al. Quality of life four years after acute myocardial infarction: short form 36 scores compared with a normal population. Heart 1999; 81: 35235 .

4. Höfer S, Kullich W, et al. Cardiac rehabilitation in Austria: long term health-related quality of life outcomes. Health and Quality of Life Outcomes 2009; 7: 99.

5. Jegier A, Szmigielska K, et al Health-Related quality of life in patients with coronary heart disease after residential vs ambulatory cardiac rehabilitation. Circ J 2009; 73: 476-83.

6. Programme on mental health WHOQOL User Manual. 1998. WHO/MNH/MHP/98.4.rev.1.

7. Somasiri KG, Gunawardena S, et al. Assessment of quality of life using Sinhala translation of WHOQOL-100. Abstracts in Annual academic sessions Galle Medical Association, 2003.

8. Brink E, Grankvist G, et al. Health-related quality of life in women and men one year after acute myocardial infarction. Quality of Life Research 2005; 14: 749-57.

9. McBurney CR, Pharm.D, et al. Health-Related Quality of Life in Patient 7 Months After a Myocardial Infarction Factors Affecting the Short Form-12. Pharmacotherapy 2002; 22(12): 1616-22.

10. Somasiri KG, Gunawardena S, et al. Quality of life of patients with hypertension attending medical clinics for treatment. Abstracts in Annual academic sessions Galle Medical Association, 2003.

11. Failde II and Soto MM. Changes in health related quality of life 3 months after an acute coronary syndrome. BMC Public Health 2006; 6: 18.

12. Rawles J, Light J, et al. Quality of life in the first 100 days after suspected acute myocardial infarction - a suitable trial endpoint? Journal of Epidemiology and Community Health 1992; 46: 612-6. 